\title{
Development and Application of Digital Media Design in Basic Education During Epidemic Period
}

\author{
Zhang Yuan ${ }^{1, a}$, Tu Zihan ${ }^{2, b^{*}}$ \\ ${ }^{1}$ School of Art \& Design Wuhan Institute of Technology Hubei China \\ ${ }^{2}$ School of Art \& Design Wuhan Institute of Technology Hubei China \\ a9557764@qq.com \\ b*1453842550@qq.com
}

\begin{abstract}
In today's rapid development of information society, the previous education methods and curriculum structure have been unable to meet the needs of talent training in modern society. To explore the rich and diversified information resources sharing channels of digital media design technology, summarize the advantages of digital media teaching methods and models in basic education, especially the overall situation of the implementation of basic education during the epidemic period. This paper analyzes different online course resources, network live teaching platform, teaching effect and derivative problems, compares the teaching activities during SARS in 2003, and explores the advantages and disadvantages of different modes of digital media in the teaching field, as well as the opportunities and challenges, so as to explore the development prospects of digital media education in the new era. Based on the theory and case study, we know that online teaching needs the careful design of teachers, the cooperation of students' parents and the support of the whole social communication network. Due to the lack of systematic thinking and long-term plan, insufficient training for teachers, it is difficult to avoid formalism in the teaching process, so it is necessary for schools to choose or use different teaching modes in combination with their own actual situation.
\end{abstract}

Keywords: Basic education, multi-media teaching, digital media design education, emergency response

\section{INTRODUCTION}

With the rapid development of Internet technology, the network has become a necessary tool for people's survival. Digital network education mode has gradually attracted people's attention and promotion, and occupies a unique advantage in teaching. Therefore, in recent years, the development of multimedia education in primary and secondary schools and universities is in full swing. In view of the situation that many schools across the country are completely closed due to the epidemic situation, the digital media network teaching mode highlights its strong technical advantages and humanized emergency measures.

However, there are still many problems and challenges in the development of education, such as uneven distribution of educational resources, limited management level and so on. Therefore, to measure the pros and cons of its development, we need to take a macro view from the time dimension. Compared with the traditional teaching mode in the past, digital media teaching has brought a new possibility to education. Primary and secondary schools across the country still vigorously encourage teachers to carry out digital teaching and system planning, and constantly optimize the teaching method in the teaching process. For example, how to properly deal with the management of teaching work in a timely manner, pacify students' physical and mental health, strengthen students' civic awareness and crisis awareness in a timely manner, and strive to minimize the harm is the most urgent work at present. Through the response to the outbreak of teaching crisis, the development of digital media in basic education has made a more solid step forward. 


\section{APPLICATION OF DIGITAL MEDIA IN PRACTICAL TEACHING DURING EPIDEMIC PERIOD}

\subsection{Advantages of digital media in basic education}

\subsubsection{Optimizing classroom teaching mode}

At present, most of the classrooms are equipped with multi-function console, projector and other hardware. To a certain extent, the configuration of digital media equipment can help teachers to create a good learning atmosphere in classroom teaching. On the whole, through multimedia digital education, the traditional single education mode has been changed, and students' attention has been attracted from vision, hearing and many other senses. The teaching form of immersion classroom helps to greatly improve the teaching quality and learning efficiency.

\subsubsection{Improve the effect of classroom teaching}

The digital media era has created a new education mode. Teachers use a variety of educational technology resources to find problems and defects in students' learning through data recording, and strengthen students' knowledge integration. With the promotion and development of mobile devices, information-based education platform makes the teaching form more convenient and flexible. Improve the efficiency of teaching, so that students and teachers can have more time to study their extracurricular areas of interest, forming a virtuous circle, the classroom communication between teachers and students, the content will be more rich, more is the sharing and analysis of content knowledge, the essential purpose of modern education and digital technology is to improve the quality and efficiency of education.

\subsubsection{Building Digital Campus}

Digital campus refers to the digital storage of all educational resources, the creation of digital commons, and the construction of a virtual campus resource library with realistic basis. The general school digital campus platform mainly includes providing multimedia courseware, electronic teaching plan, test database, learning website and so on, so as to realize resource sharing. The online interaction between teachers and students can also complete question answering, exchange and interaction, realize personalized and differentiated education guidance, and optimize education mode.

\subsubsection{Improving teachers' innovative consciousness and ability}

To strengthen the development of modern basic education and digital technology, it is necessary to strengthen the requirements for teachers' innovative consciousness and ability. For example, making teaching courseware includes theme setting, data collection and production, explanation method, video recording, synthesis and final production and release. Therefore, digital media can help teachers play a leading role in the classroom. It can not only mobilize teachers' initiative and participate in modern information basic education, but also continuously improve the innovation ability of education and teaching.

\subsection{The overall situation of the implementation of basic education during the epidemic period}

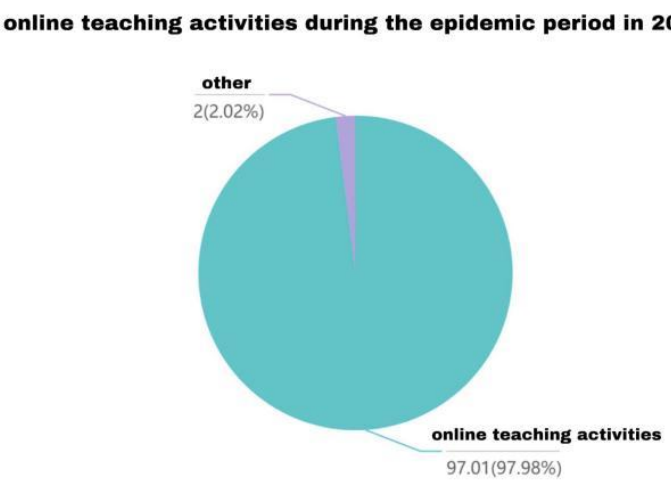

Figure 1 online teaching activities during the epidemic period in 2020

During the new coronavirus period, the central and local governments have issued corresponding teaching arrangements, which require schools to strengthen the organization and operation management, provide technical services, strengthen training guidance, and ensure scientific and orderly implementation. Hubei Province, as a severe epidemic area, requires local education administrative departments to integrate and mobilize education resources according to the requirements, teaching scale and conditions. In February 2020, a small-scale online questionnaire survey was conducted on the students' participation in online teaching during the epidemic period in Hubei Province. $97.01 \%$ of the students said that almost all of them actively responded to the call of many Ministry of education to carry out the relevant teaching work of "class suspension without school suspension". 


\section{CASE ANALYSIS OF DIGITAL MEDIA IN BASIC EDUCATION DURING EPIDEMIC PERIOD}

\subsection{Online course resources}

With the rise of digital infrastructure construction in higher education and the popularization of various teaching reforms in basic education, there are higher requirements for front-line teachers to use digital media for teaching. In the face of the delay of school opening caused by the epidemic situation, online curriculum resources play a multiplier effect in the limited time. This reflects the necessity and importance of teachers' ability to make online courses and carry out online teaching. For example, more than $70 \%$ of the students use smart phones, and only $1 \%$ of the parents say they have no Internet TV or mobile devices. As shown in the table in Figure 2, with the development of digital technology in basic education, 4G network coverage and the popularity of mobile phone clients have played an irreplaceable role in assisting students' home online learning.

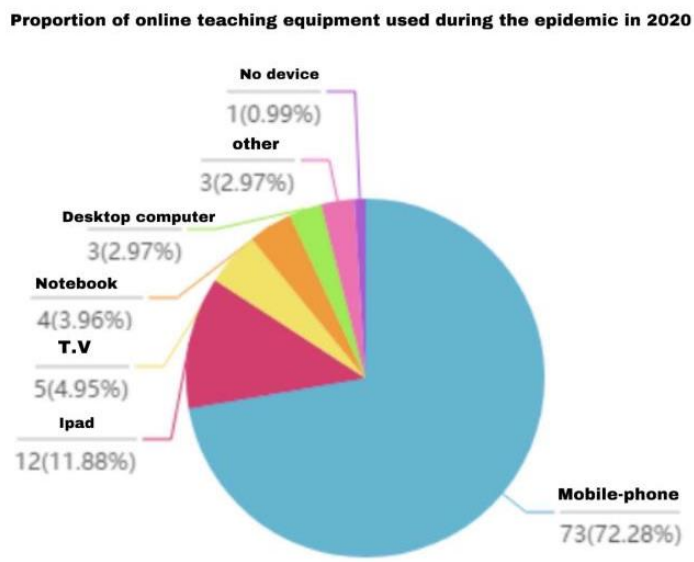

Figure 2 Proportion of online teaching equipment used during the epidemic in 2020

\subsection{Network live teaching platform}

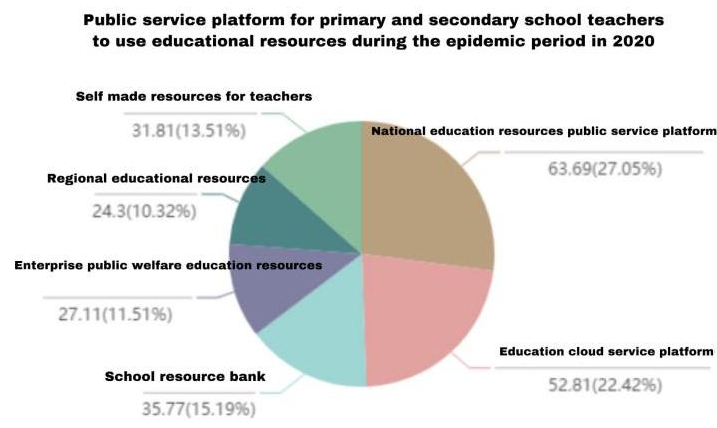

Figure 3 Public service platform for primary and secondary school teachers to use educational resources during the epidemic period in 2020
The development of mobile Internet, to a certain extent, drives the prevalence of live culture. As a new way of online learning, it gradually occupies a dominant position and has been recognized and used by more and more people. Various platforms, such as zoom, umu, cctalk, superstar learning, have emerged one after another, which is more attractive to today's young people. At the same time, it is not difficult to find that the network live breaks the original single and fixed teaching mode, breaks through the time and space constraints, as a more direct, convenient, effective and flexible teaching method, shortens the distance between teachers and students, enhances the interaction between teachers and students, and has become a new and efficient teaching form of distance learning for teachers and students.

\subsection{Teaching effect and its derivative problems}

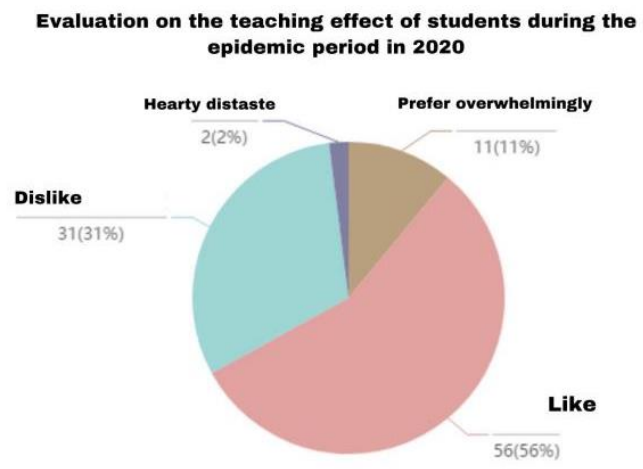

Figure 4 Evaluation on the teaching effect of students during the epidemic period in 2020

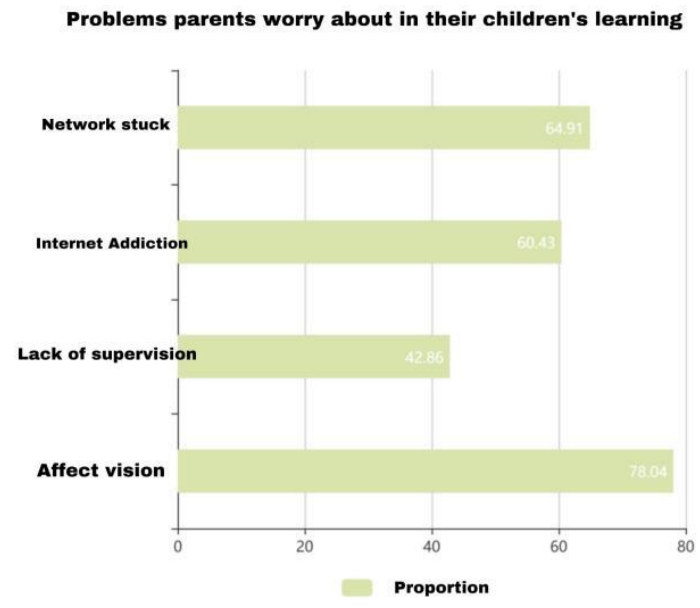

Figure 5 Problems parents worry about in their children's learning

During the special epidemic period, due to the inability to complete the lessons according to the usual work and rest time, the self-study was cancelled. The course schedule was allocated by the teachers of various disciplines independently, and then the lessons were taught through some corresponding live broadcast platforms. Therefore, the organization of teachers' long- 
distance counseling and question answering, students' autonomous learning as the main form, has become the first choice of most schools. According to the Bureau's data, due to the low utilization rate of multimedia facilities in some areas, only about $50 \%$ of the courses are taught through multimedia every day, so it is difficult for some primary and secondary schools in rural areas to use multimedia teaching every day. The reason lies in the lack of teachers' ability to use. In fact, most young teachers have a high level of computer application, but for older teachers, learning computer application is relatively difficult. At the same time, some students reflect that in multimedia teaching, most of the teachers just read PPT, or share the resources of online courses, take the teaching form of self-study and answer questions, the teaching pace is too fast, or cope with learning tasks. Therefore, the teaching content should pay attention to grasp the key and difficult points, pay attention to the interactive communication in class, so that the technology can better assist the class, and also require students to learn to adapt to different teaching modes ( This statistic reflects that traditional education still plays a very important role in the current education work. It shows that multimedia teaching cannot completely replace traditional teaching, and its purpose is not to replace traditional teaching, but to better assist teachers to complete teaching tasks efficiently.

\subsection{Comparison of teaching activities during SARS in 2003}

In 2003, 17 years ago. At that time computer mobile phone was novel coronavirus pneumonia, and there were few media that could provide network information. Therefore, during the 03 years of SARS, information transmission and renewal and information dissemination and renewal of the new crown pneumonia epidemic situation were far from comparable. In addition, 2003 is also the first year of the college entrance examination in China. The epidemic broke out. In March and April, the school closed down. In mid-May, the school closed down. Students were given review materials to let them go home and study independently. Entertainment programs on TV stations were all stopped, and TV classes were changed to make way for college entrance examination students. Generally speaking, the TV classroom, jointly launched by the education department, TV stations and major communication operators, had a wide coverage and strong stability at that time. In addition, the school formulated a detailed schedule of work and rest and broadcast it according to the scheduled time. The national accompanying examination activity was vigorously launched. However, the form was mainly one-way transmission of teaching related content, and the interaction was weak, It is a great test for learners' self-control.

\subsection{Summary}

From the above four perspectives, it is not difficult to find that in terms of the media of communication, its timeliness, coverage and learning mode, the digital media teaching mode still has advantages and disadvantages in the actual daily teaching work. Although the network resource platform has enriched today's teaching mode, there is a situation that "things can't make the best use of them". This not only requires teachers to prepare the courseware carefully, but also needs the cooperation of students' parents and the support of the whole social communication network. Compared with the past TV class, the network live teaching can make both sides participate in the learning process. In the form of distance teaching, students' autonomous learning also tests each student's selfcontrol. Therefore, it is necessary for all schools to proceed from their own actual situation, and teachers should deliberately create more appropriate communication opportunities in the network teaching, Appropriate and suitable learning tasks and activities are arranged to enable students to participate in the daily teaching content with the purpose of answering, so as to promote more interaction and understanding opportunities between students and between teachers and students, which fully reflects the teaching concept of interaction between teachers and students, students and learning resources in digital campus.

\section{CONCLUSION}

Nowadays, digital media technology has a broader development space in China's education industry. Compared with the sudden epidemic in 2003, the National Education Department has a more efficient response plan. Through this epidemic, it is not difficult to see the fact that based on its advanced and huge social communication technology, and carry forward the glorious tradition of the whole society to concentrate on big things, It's easy and comfortable for everyone to carry out online teaching. The epidemic situation has blocked the physical distance between people, but it can't stop the Chinese people's determination to face unexpected problems and solve problems. The development advantages and bottlenecks of digital media in the education industry should be viewed from the time dimension. Compared with the traditional teaching mode in the past, digital media teaching brings a new possibility to education. Colleges and universities still vigorously encourage teachers to carry out digital teaching, and constantly optimize teaching methods in the teaching process. However, due to the lack of systematic thinking and long-term plan, the training of teachers' digital technology teaching ability is not sufficient, so it is difficult to avoid formalism in the teaching process. So, most of the time, the problems exposed seem to be the problems of new technology or 
decision-making, but they are actually the problems of people. In the face of the emergence of new things, in addition to acceptance, but also with the optimization of development, to better adapt to the current teaching work. Therefore, in view of the current special epidemic situation, digital media also brings more choices to teaching in response to special emergencies. I believe that through this response to the outbreak of teaching crisis, the development of digital media in basic education has made a more solid step forward.

\section{REFERENCES}

[1] Zheng K. (2020) Research on the practical teaching mode of digital media education.J,17(01):86-87.

[2] Yang R. Zhang Z. Zhang Y.(2016) Discussion on flipped classroom, micro class and MOOC.J, (3): 48-49.

[3] Sun S. Reflection and Countermeasures of public health emergencies [d]. Zhejiang University, 2004

[4] Wang X. (2010) Analysis and Countermeasures of multimedia teaching in primary and secondary schools.J,(24): 147-148

[5] Liu Yongqing Y. Chen A. (2008) Research status and theoretical research framework of Multimedia Teaching.J, Journal of Xiangtan Normal University (SOCIAL SCIENCE EDITION), (01): 185-187 